\title{
Nanocomposite Films Based on Flaxseed Gum and Cellulose Nanocrystals
}

\author{
Natália Soares Prado ${ }^{\circledR}$, Ingrid Souza Vieira da Silva ${ }^{\circledR}$, \\ Thiago Alves Lopes Silva ${ }^{\circledR}$, Welles Júnior de Oliveira ${ }^{b}$, Leila Aparecida de Castro Motta ${ }^{b} \oplus$, \\ Daniel Pasquini ${ }^{\oplus}$, Harumi Otaguro ${ }^{a}$ * \\ anstituto de Química, Universidade Federal de Uberlândia, Uberlândia, MG, Brasil \\ ${ }^{b}$ Faculdade de Engenharia Civil, Universidade Federal de Uberlândia, Uberlândia, MG, Brasil
}

Received: February 21, 2018; Revised: July 31, 2018; Accepted: August 30, 2018

\begin{abstract}
Flaxseed gum (FG)-based films were developed with the addition of glycerol as a plasticizer and glutaraldehyde as a crosslinking agent. $\mathrm{HCl}$ was added to improve crosslinking and decrease the hydrophilicity of the matrix. Different cellulose nanocrystal $(\mathrm{CN})$ amounts were used as reinforcements in the optimum FG formulation. The crosslinking process at $\mathrm{pH} 3.5$ led to a lower solubility of FG in water (from $100 \%$ to $53 \%$ ) and an increase in thermal stability (from $160^{\circ} \mathrm{C}$ to $209^{\circ} \mathrm{C}$ ). FTIR analysis confirmed a reduction in the $-\mathrm{OH}$ band due to crosslinking between the hydroxyl groups of FG. A diffuse diffraction pattern was observed for all FG films. The addition of $4 \% \mathrm{w} / \mathrm{w}$ of $\mathrm{CN}$ contributed to reduction of water solubility (from $53 \%$ to $20.8 \%$ ) and absorption (from $21.9 \%$ to $6.8 \%$ ). Finally, an improvement was observed in the tensile mechanical properties in the nanocomposites, showing satisfactory results for the proposed formulations, mainly with $8 \% \mathrm{w} / \mathrm{w}$ of $\mathrm{CN}$ added to the matrix. Overall, this study demonstrated that $\mathrm{FG} / \mathrm{CN}$ nanocomposites are promising materials to be use as a sustainable biopolymer for application as bioplastics.
\end{abstract}

Keywords: Flaxseed gum, cellulose nanocrystals, crosslinking, nanocomposite, biopolymer.

\section{Introduction}

Due to the search for and necessity of application of sustainable products, biopolymers appear for proposed use in several innovative fields, such as packaging ${ }^{1-2}$, biomedicine $^{3}$ and agriculture ${ }^{4-5}$. When evaluating different sources of biomass, flaxseed gum shows potential for these applications. It may be preferentially used as a thickener, stabilizer or emulsifier in food systems ${ }^{6}$. In cosmetic and pharmaceutical applications, it has been used as a lubricant and even as artificial mucus?

Flaxseed-based mucilage is constituted by a major neutral fraction (L-arabinose, D-xylose and D-galactose) and a minor acidic fraction (L-rhamnose, L-fucose, L-galactose, and D-galacturonic acid) $)^{8-9}$. The association of these two fractions provides a basis of interesting rheological properties (gel formation) and morphological characteristics, which are important for its final application. Flaxseed gum has also been used to strengthen the starch films, to attain better mechanical performance ${ }^{10}$. Tee and his collaborators developed an edible film based on flaxseed gum as a sustainable alternative for food coating and packaging ${ }^{11}$, and Wang and colleagues evaluated the dynamic-mechanical properties of edible films of flaxseed gum with addition of plasticizer ${ }^{12}$.

It is important to point out that the major commercial interest is often in flaxseed oil, but it is possible to add value to the flaxseed gum and husk. In this way, studies to know better the physical-chemical properties of flaxseed gum and its capacity for film formation become relevant, and justifies the interest in its applications as a bioplastic.

It is well established that natural gums exhibit undesirable properties, such as high hydration rates that restrict their use in specific applications or in high humidity media ${ }^{13}$, and inadequate mechanical properties, such as fragility and brittleness.

The insertion of plasticizers and crosslinking agents may avoid or minimize some of these inconveniences, as an expected consequence of altering the properties of such added materials according to the target product.

Plasticizers such as glycerol (GLY), propylene glycol or polyethylene glycol ${ }^{14}$ are commonly used to increase film flexibility through reducing hydrogen bonds along the polymer, leading, as a consequence, to a rise intermolecular spacing ${ }^{15}$ and the molecular mobility of the polymer chains.

Chemical crosslinking produces intermolecular bonds between polymer chains ${ }^{16}$ which increase water resistance, cohesion, stiffness and mechanical strength ${ }^{17}$. Crosslinking involves the use of crosslinking agents such as genipine, glutaraldehyde (GLA) and formaldehyde ${ }^{14}$. GLA is the mostused crosslinking agent due to its low $\cos ^{18}$ and its ability to provide a higher water resistance of the obtained material ${ }^{19}$.

Bao and collaborators reported the most favorable acid media conditions for crosslinking of agar with glutaraldehyde ${ }^{20}$. Crosslinking of polyvinyl alcohol with glutaraldehyde in acidic medium was also proposed by Reis and collaborators ${ }^{21}$. 
Cellulose nanocrystals have been applied in several areas including drugs ${ }^{22}$, packaging ${ }^{23}$, medicine ${ }^{24}$ and the textile industry ${ }^{25}$, aimed primarily at reinforcement. Because it has desirable properties, such as transparency and rigidity, and being an abundant, biodegradable material, it has aroused great commercial interest with competitive advantages over fossil and industrialized materials ${ }^{26}$.

In an attempt to minimize these problems and enable use of FG as a bioplastic, we developed flaxseed gum films with glycerol, glutaraldehyde, and addition of $\mathrm{HCl}$. The film with lower water solubility will be taken as the standard for the nanocomposites development with different levels of cellulose nanocrystals $(2,4$ and $8 \% \mathrm{w} / \mathrm{w})$. The effects of crosslinking on the thermal and morphological properties, as well as changes in chemical structure, were examined by thermal gravimetric analysis (TGA), X-ray diffraction (XRD) and Fourier Transform infrared (FTIR), respectively. Moreover, solubility, water absorption, water contact angle, and mechanical tensile strength of films and nanocomposites were measured. Scanning electron microscopy (SEM) images were also collected. As far as know, there have been no reports in the literature on flaxseed gum/cellulose nanocrystal nanocomposite studies.

\section{Experimental}

\subsection{Materials}

Flaxseed golden grains were purchased from a local supermarket (Cereale - Uberlândia, Minas Gerais, Brazil). Other reagents were: phosphorus pentoxide $\left(\mathrm{P}_{2} \mathrm{O}_{5}, 98.5 \%\right.$; Sigma-Aldrich), glycerol (Isofar), glutaraldehyde solution ( $50 \mathrm{wt} \%$ in $\mathrm{H}_{2} \mathrm{O}$; Sigma Aldrich), hydrochloric acid (Vetec), potassium chloride (99-100\%; Vetec), Eucalyptus bleached Kraft pulp and sulfuric acid (Vetec).

\subsection{Preparation of cellulose nanocrystals}

The CNs were isolated from bleached Kraft pulp (KP) of Eucalyptus urograndis (Eucalyptus urophila hybrid and Eucalyptus grandis). The experimental conditions of the $\mathrm{CN}$ process were reported by Da Silva and collaborators ${ }^{23}$. The CNs were prepared by hydrolysis at $45^{\circ} \mathrm{C}$ for $50 \mathrm{~min}$. For each gram of fiber we used $20 \mathrm{ml}$ of $\mathrm{H}_{2} \mathrm{SO}_{4} 60 \mathrm{wt} \%$.

\subsection{Extraction of flaxseed gum}

The seeds (240 g) were soaked in distilled water (960 $\mathrm{mL})$ at room temperature $\left(25 \pm 1^{\circ} \mathrm{C}\right)$ for approximately 18 h. After this time, more distilled water $(800 \mathrm{~mL})$ was added and vigorously stirred for $15 \mathrm{~min}$. Finally, two filtrations were performed to separate the gum. The total suspended solids for FG suspension was analyzed by drying and resulted in $0.9 \% \mathrm{w} / \mathrm{w}$.

\subsection{Preparation of flaxseed gum films}

Based on preliminary tests, the amounts of glycerol and glutaraldehyde were fixed at $30 \% \mathrm{w} / \mathrm{w}$ and $15 \% \mathrm{w} / \mathrm{w}$, respectively, using $2.0 \mathrm{~g}$ total dry mass of flaxseed gum in the formulation. The criteria used to choose the formulation was based in the flexibility, appearance and uniformity of the obtained films. The pure flaxseed gum (FG) films were prepared using only the gum suspension. The gum suspension and additives were mixed under stirring for $10 \mathrm{~min}$. For the $\mathrm{FG}_{\mathrm{GLY} / \mathrm{GLA} / \mathrm{HCl}}$ formulation the flaxseed gum strain was previously acidified with $1.5 \mathrm{M} \mathrm{HCl}$ to $\mathrm{pH} 3.5$. All films were obtained, by a casting method, into petri dishes with dimensions of $150 \mathrm{~mm} \times 15 \mathrm{~mm}$ and placed in an oven, Jeio Tech model OF-02, with air circulation at $35^{\circ} \mathrm{C}$ for $48 \mathrm{~h}$. Due to preliminary solubility tests, $\mathrm{FG}_{\mathrm{GLY} / \mathrm{GLA} / \mathrm{HCl}}$ formulations was chosen as the control sample to obtain the nanocomposites.

\subsection{Preparation of flaxseed gum nanocomposites}

As mentioned above in the text, $\mathrm{FG}_{\mathrm{GLY} / \mathrm{GLA} / \mathrm{HCl}}$ formulation was chosen as the control sample to obtain the nanocomposites. For the nanocomposites preparation 2, 4 and $8 \% \mathrm{w} / \mathrm{w}$ of $\mathrm{CN}$ was added together with the suspension of gum and additives. The nanocomposites were named $\mathrm{FG}_{2 \% \mathrm{CN}}, \mathrm{FG}_{4 \% \mathrm{CN}}$ and $\mathrm{FG}_{8 \% \mathrm{CN}}$ according to the cellulose nanocrystal content.

\subsection{Thermal gravimetric analysis (TGA)}

Thermal stability of the films were evaluated using Shimadzu DTG-60H equipment. The analysis conditions were: a nitrogen atmosphere with flow rate of $50 \mathrm{~mL} \mathrm{~min}^{-1}$, a heating rate of $10^{\circ} \mathrm{C} \mathrm{min}^{-1}$, a temperature range of 25 to $600{ }^{\circ} \mathrm{C}$, and a sample mass between 5 and $7 \mathrm{mg}$. The initial temperature of degradation $\left(\mathrm{T}_{\text {onset }}\right)$ was defined as the intersection of the tangents drawn from the thermogravimetric curves.

\section{$2.7 X$-ray diffraction $(X R D)$}

X-ray diffractograms for all films, nanocomposites, and cellulose nanocrystals were obtained at room temperature over a $2 \theta$ range from 5 to 40 at a scan rate of $4^{\circ} \mathrm{min}^{-1}$ using a Shimadzu LabX XRD-6000 operating at a power of $40 \mathrm{kV}$ with a current of $30 \mathrm{~mA}$ and $\mathrm{CuK} \alpha$ radiation (1.5406 $\AA$ ).

\subsection{Atomic force microscopy (AFM)}

Atomic Force microscopy (AFM) was analyzed using the Shimadzu SPM-9600 equipment. A droplet of the aqueous CNCs suspension $\left(1 \times 10^{-4} \mathrm{~g} \mathrm{~mL}^{-1}\right)$ was deposited onto a freshly cleaved mica surface and air-dried. AFM images were captured with a scan rate of $1 \mathrm{~Hz}$ using Si tips with a curvature radius of less than $10 \mathrm{~nm}$ and a spring constant of $42 \mathrm{~nm}^{-1}$. The dimensions of the nanocrystals were determined using VectorScan software. 


\subsection{Fourier transform infrared (FTIR) analysis}

FTIR experiments were performed to collect spectra of films and nanocomposites using a Shimadzu IRPrestige-21. The sample and $\mathrm{KBr}$ were mixed and compacted in a weight ratio of 1:100. The experiments were carried out over the range of $400-4000 \mathrm{~cm}^{-1}$, with a resolution of $4 \mathrm{~cm}^{-1}$ and 32 scans per sample.

\subsection{Scanning alectron microscopy (SEM)}

The fracture region of samples was analyzed with a TECAN model Vega3 scanning electron microscope. Samples were fractured after immersion in liquid nitrogen, fixed on aluminum supports with carbon tape, and metallized with gold. SEM images were obtained at $3500 \mathrm{x}$ magnification and with an acceleration voltage of $5.0 \mathrm{kV}$.

\subsection{Solubility $(S)$}

Three aliquots of each film formulation and nanocomposite (diameter of $2 \mathrm{~cm}$ ) were dried in an oven at $105^{\circ} \mathrm{C}$ for 2 $\mathrm{h}$. This condition was determined by successive weighing until there was no discernible mass variation. After that, each sample was weighed to determine the initial dry matter $\left(w_{b}\right)$, and then immersed in $30 \mathrm{~mL}$ distilled water in a beaker. The beaker was sealed and periodically stirred up to $24 \mathrm{~h}$ at $23 \pm 2{ }^{\circ} \mathrm{C}$. Finally, the insoluble portion of the sample was removed, oven dried at $105^{\circ} \mathrm{C}$ for $24 \mathrm{~h}$ and weighed $\left(w_{f}\right)$ to determine the weight of the solubilized dry matter. Water solubility of each film was determined by Eq. (1).

$$
\text { Solubility }(\%)=\left[\frac{w_{i}-w_{f}}{w_{i}}\right] \times 100
$$

\subsection{Water absorption (Wa)}

$\mathrm{Wa}$ experiments were conducted with three replica of each sample and nanocomposite $(2 \mathrm{~cm}$ diameter) which were dried in an oven at $105^{\circ} \mathrm{C}$ for $2 \mathrm{~h}$. After drying, they were removed from the oven and stored in a desiccator with silica until weighing $\left(w_{i}\right)$. The samples were then transferred into a desiccator containing potassium chloride solution $(\mathrm{RH}=$ $85 \%)$ prepared according to the standard ASTM E104-02, as described in the work of Babaee and collaborators ${ }^{27}$. The weight of the samples after water absorption was recorded by periodically withdrawing them from the desiccator at intervals of $0.5,1,2,4$ and $8 \mathrm{~h}$. The process was followed up to steady state $\left(w_{f}\right)$, where the value of several consecutive weighings did not demonstrate relevant absorption. The measurements of $W a$ were carried out using Equation (2).

$$
W a(\%)=\left[\frac{w_{i}-w_{f}}{w_{i}}\right] \times 100
$$

\subsection{Contact angle}

The water contact angle measurement data were collected in an Attension Theta Lite TL100 Optical Tensiometer operated at room temperature $\left(25 \pm 1^{\circ} \mathrm{C}\right)$. Samples of $(2 \mathrm{~cm} \times 1 \mathrm{~cm})$ were cut and fixed with double-sided adhesive tape. The sessile drop method was used, based on measuring the contact angle between a water droplet and the surface of the film (sample) with a syringe. The drop image was captured by a camera coupled to the computer and the contact angle calculated by the measurement average for $2 \mathrm{~s}$. Through the stored images, the software determined the contact angle by fitting a mathematical expression to the Young-Laplace shape and calculating the slope of the tangent to the drop at the liquid-solid-vapor interface. This assay was performed in triplicate and values are given as medium values and standard deviation.

\subsection{Elemental analysis}

The carbon, hydrogen, and nitrogen content of the films were determined with a CE Instruments EA1110-CHN/O elemental analyzer. The protein content (\%) of the samples was calculated by multiplying the nitrogen content (\%) by $6.25^{28-29}$.

\subsection{Tensile tests}

The tensile behavior of films and flaxseed gum nanocomposites was analyzed using an Instron 5982 universal testing machine with $5 \mathrm{kN}$ load cell according to ASTM D 882-02 and as described in the work of Kumar and collaborator ${ }^{30}$. The experiments were performed at room temperature with a crosshead speed of $25 \mathrm{~mm} \mathrm{~min}^{-1}$ using rectangular strips (1 $\mathrm{cm} \times 9 \mathrm{~cm}$ ) samples. The distance between the claws was 5 $\mathrm{cm}$, and the thickness was measured before each run. Before analysis, the samples were conditioned at $25 \pm 2{ }^{\circ} \mathrm{C}$ and controlled relative humidity $(59 \% \mathrm{RH}$ - sodium bromide solution) for at least 5 days. The thickness of the samples was measured using the micrometer (Zaas precision); the values and standard deviation from five aleatory points into the selected film area are reported in the Table 4 . The tensile strength at break $(\sigma)$, elongation at break ( $(\varepsilon)$ and Young's modulus (E) were determined from these films. Ten samples were assayed for each formulation.

\section{Results and Discussion}

\subsection{Thermal gravimetric analysis (TGA)}

The TGA curves shown in Figure 1 for the flaxseed gum films and nanocomposites obtained from neat $\mathrm{FG}$, $\mathrm{FG}_{\mathrm{GLY} / \mathrm{GLA}}$ and $\mathrm{FG}_{\mathrm{GLY} / \mathrm{GLA} / \mathrm{HCl}}$, exhibit a slight decrease in mass $(\sim 5 \%)$ starting below $100^{\circ} \mathrm{C}$, which can be attributed to water evaporation. The $\mathrm{T}_{\text {onset }}, \mathrm{T}_{\text {max degradation }}$ and $\%$ residue 


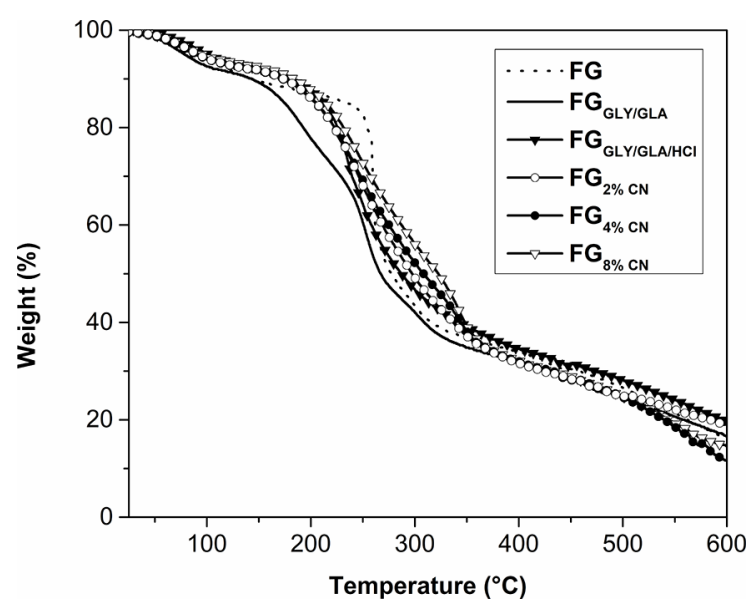

Figure 1. TGA curves for films made from FG films and nanocomposites.

are presented in Table 1. The other mass losses are related to the degradation of macromolecular chains and additives. It can be seen that the thermal stability $\left(\mathrm{T}_{\text {onset }}\right)$ decreased from $256{ }^{\circ} \mathrm{C}$ for neat $\mathrm{FG}$ to $160{ }^{\circ} \mathrm{C}$ with crosslinking and plasticizer agent addition $\left(\mathrm{FG}_{\mathrm{GLY} / \mathrm{GLA}}\right)$. The glycerol addition decreases the thermal stability of the flaxseed gum matrix because it acts as a polymer chains separator decreasing the interactions between them. This effect was also reported by Da Silva and collaborators ${ }^{23}$ in a pectin matrix. This explains the decrease in $\mathrm{T}_{\text {onset }}$ from $256^{\circ} \mathrm{C}(\mathrm{FG})$ to $160^{\circ} \mathrm{C}$ $\left(\mathrm{FG}_{\mathrm{GLY} / \mathrm{GLA}}\right)$. On the other hand, this effect was minimized in acid medium as can be observed by the increase of 160 ${ }^{\circ} \mathrm{C}$ to $209^{\circ} \mathrm{C}$. Suggesting that glutaraldehyde did not act as a crosslinking agent because crosslinked polymers are expected to exhibit a higher thermal stability than the starting polymer. With the addition of acid, however, the $\mathrm{FG}_{\mathrm{GLY} /}$ GLA/HCl film showed higher thermal stability, with a $\mathrm{T}_{\text {onset }}$ of $209^{\circ} \mathrm{C}$. Which suggest an increase crosslinking efficiency between the polymeric chains. Finally, higher residue levels were obtained for all samples, which may be related to the presence of minerals in the gum which precipitate as salts. Mazza and collaborators reported the presence of potassium, calcium, phosphorus and magnesium in the extraction of gum $^{31}$, which corroborates the obtained waste values. The nanocomposites thermal stability (Figure 1 and Table 1) was very close compared to the control film $\left(\mathrm{FG}_{\mathrm{GLY} / \mathrm{GLA} / \mathrm{HCl}}\right)$. This indicates that the addition of $\mathrm{CN}$ did not alter the thermal stability of the control film.

\section{$3.2 X$-ray diffraction $(X R D)$}

A diffuse diffraction pattern was observed for all flaxseed gum films and CN (Figure 2). This pattern is characteristic of amorphous polymers ${ }^{32}$ and has two distinct halos. The van der Waals halo is seen at $2 \theta$ values of $18-20^{\circ}$. The low van der Waals halo is at $2 \theta$ values of $10-13^{\circ}$. The displacement to higher values of $2 \theta$ for both halos may be explained by the complexes structure of flaxseed gum. In the case of the
Table 1. Thermal stability $\left(\mathrm{T}_{\text {onset }}\right.$ and $\left.\mathrm{T}_{\max \text { degradation }}\right)$ and residue $\%$.

\begin{tabular}{lccc}
\hline Samples & $\begin{array}{l}\mathbf{T}_{\text {onset }} \\
\left({ }^{\circ} \mathbf{C}\right)\end{array}$ & $\begin{array}{c}\mathbf{T}_{\text {max degradation }}\left({ }^{\circ} \mathbf{C}\right) \\
\text { FG }\end{array}$ & \% residue \\
FG $_{\text {GLY/GLA }}$ & 256 & 260 & 16 \\
$\mathbf{F G}_{\text {GLY/GLA/HCl }}$ & 160 & 253 & 16 \\
$\mathbf{F G}_{\mathbf{2} \% \mathbf{C N}}$ & 209 & 235 & 20 \\
$\mathbf{F G}_{\mathbf{4} \% \mathbf{C N}}$ & 196 & 249 & 19 \\
$\mathbf{F G}_{\mathbf{8 \% ~ C N}}$ & 203 & 254 & 11 \\
\hline
\end{tabular}

$\mathrm{FG}_{\mathrm{GLY} / \mathrm{GLA} / \mathrm{HCl}}$ film, the X-ray pattern shows a decrease in the low van der Waals intensity halo and a shift to lower values, an indication of a reduction in the two-dimensional order or a larger structural organization. The presence of $2 \theta$ peaks at $15^{\circ}, 22.5^{\circ}$ and $34^{\circ}$ to $\mathrm{CN}$ is attributed the predominance of cellulose type $\mathrm{I}^{33}$. The peak at 34 ? of $2 \theta$ is preferably found in $\mathrm{CN}$ than into nanocomposites, due to the incorporate quantity, but the peak still there masked by the influence of matrix and additives. An increase in the intensity of these peaks with $\mathrm{CN}$ content was observed, which carried out an increase degree of crystallinity to the FG films.

\subsection{Atomic force microscopy (AFM)}

The AFM images in Figure 3 show isolated cellulose nanocrystals. The $\mathrm{CN}$ displays a rod-like shape with an average length of $155 \pm 27 \mathrm{~nm}$, an average diameter of $4 \pm$ $1 \mathrm{~nm}$, and an aspect ratio of $37 \pm 10$.

\subsection{Fourier transform infrared analysis (FTIR)}

The changes in the chemical structure of the films after addition of the plasticizer and crosslinking agent, as well as $\mathrm{CN}$ insertion, were evaluated using FTIR (Figure 4). A broad absorption band at $3357 \mathrm{~cm}^{-1}$, attributed to hydroxyl groups stretching was observed for all sample curves. An

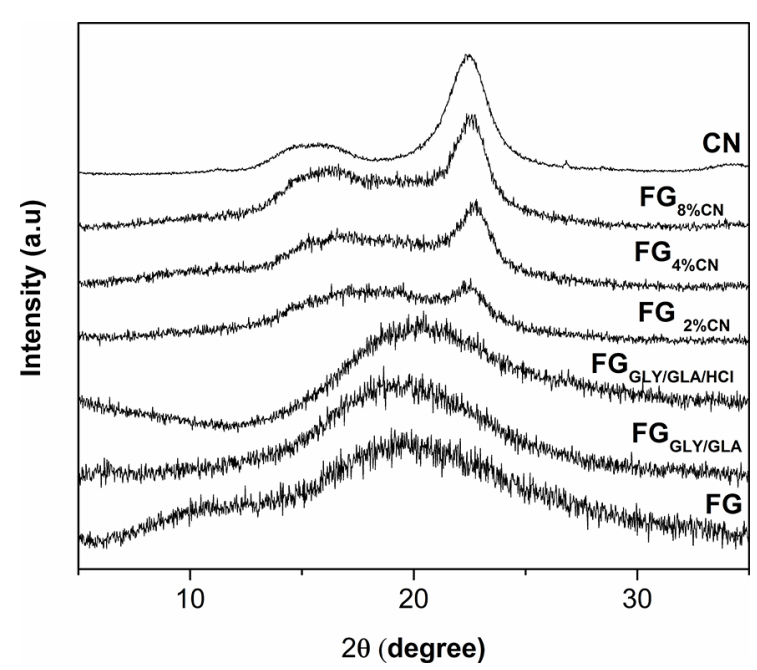

Figure 2. XRD patterns for films, nanocomposites and cellulose nanocrystal. 

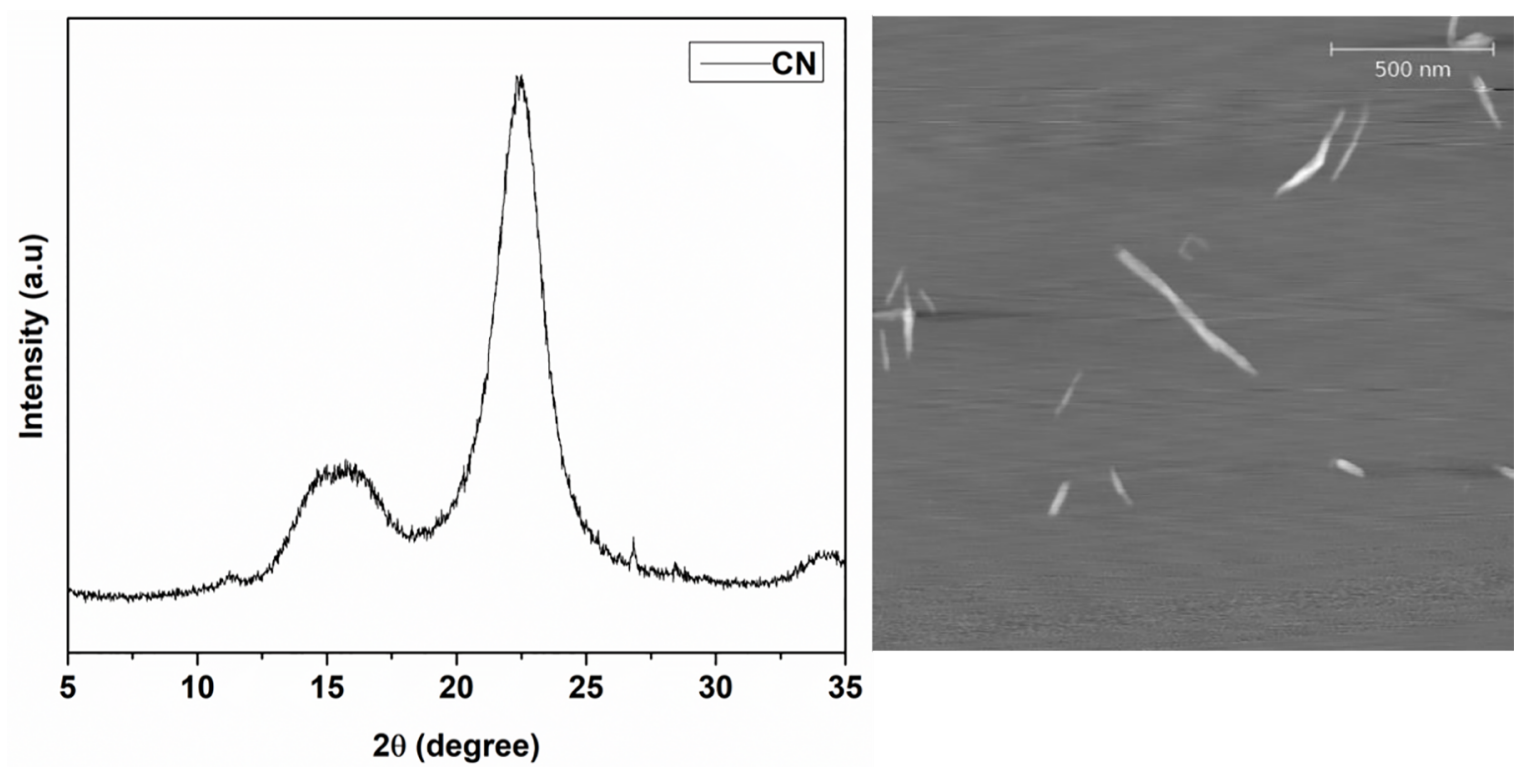

Figure 3. XRD pattern of $\mathrm{CN}$ and (b) atomic force microscopy image of $\mathrm{CN}$.

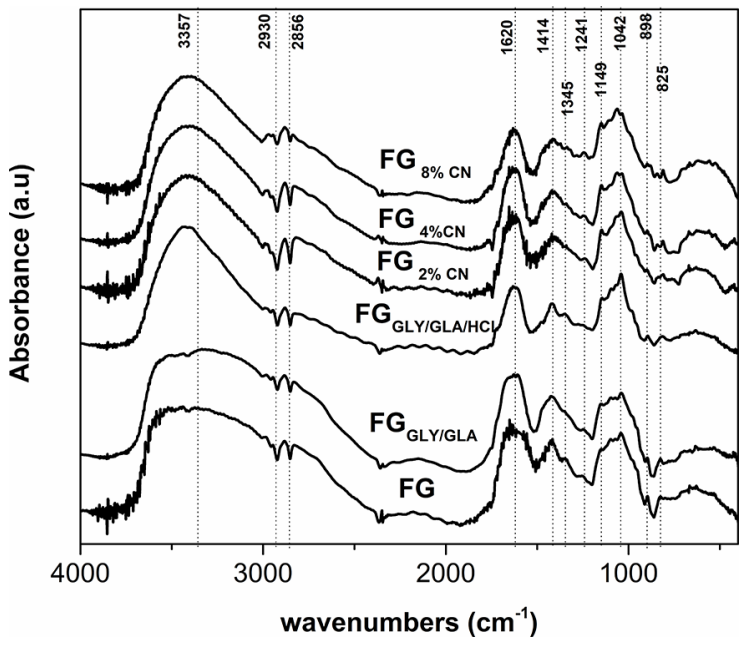

Figure 4. FTIR spectra for all FG films and nanocomposites

absorption at $\sim 2930 \mathrm{~cm}^{-1}$ was attributed to the $\mathrm{C}-\mathrm{H}$ bonds of the $\mathrm{CH}_{2}-\mathrm{CH}_{3}$ groups of aliphatic chains. The corresponding symmetrical stretching was observed at $2856 \mathrm{~cm}^{-1}{ }^{34}$. The peak at $1620 \mathrm{~cm}^{-1}$ in the spectrum is characteristic of the $\mathrm{C}=\mathrm{O}$ stretching vibrations of galacturonic acid and the presence of water. The scissor-type vibrations of the $-\mathrm{CH}_{2}$ and $-\mathrm{OH}$ bonds contribute to signals at 1414 and $1345 \mathrm{~cm}^{-1}$, respectively. Symmetric C-O-C stretching vibrations appeared at 1241 $\mathrm{cm}^{-1}$, while a strong absorbance at $1042 \mathrm{~cm}^{-1}$ is attributed to asymmetric stretching vibrations of C-O-C bonds ${ }^{35}$. Vibration elongation of $\mathrm{FG}$ branches produces spectrum absorption lines at 898 and $825 \mathrm{~cm}^{-1}$ 35. The absorption band at 1149 $\mathrm{cm}^{-1}$ corresponds to the glycoside bond C-O-C $\mathrm{C}^{36}$.

A reduction in the $\mathrm{OH}$ band can also be observed for $\mathrm{FG}_{\mathrm{GLY} / \mathrm{GLA} / \mathrm{HCl}}$ and the nanocomposites due to crosslinking between the hydroxyl groups of flaxseed gum polysaccharides.
It could be predicted that the modification caused by crosslinking would not be observed by infrared because the bridges formed by glutaraldehyde contain only $\mathrm{CH}_{2}-\mathrm{CH}_{2}$ bonds and ether bonds (C-O-C), both already existing in the polysaccharide structure. Bao et al. also failed to show changes in the infrared spectrum after crosslinking of agar with glutaraldehyde ${ }^{20}$.

In the case of $\mathrm{FG}$ nanocomposites $\left(\mathrm{FG}_{2 \% \mathrm{CN}}, \mathrm{FG}_{4 \% \mathrm{CN}}\right.$ and $\mathrm{FG}_{8 \% \mathrm{CN}}$ ), no major differences were observed in the absorption peaks with the addition of $\mathrm{CN}$, because of the similarity of the functional groups in comparison with glycerol and glutaraldehyde.

\subsection{Elemental analysis}

The presences of protein contaminants may also modify the film morphology. Therefore, the carbon, hydrogen, and nitrogen contents were measured to evaluate protein contaminants in flaxseed gum (Table 2). The protein content was $5.81 \%$ for the FG film. Kaushik and collaborators reported that protein content in the FG samples increased significantly from $4.4 \%$ to $15.1 \%$ when the extraction temperature was raised from 30 to $90{ }^{\circ} \mathrm{C}^{28}$.

\subsection{Scanning electron microscopy (SEM)}

The cryo-fractured films and nanocomposites observed by SEM are shown in Figures 5 and 6, respectively. The FG film showed a rough and irregular cross-section compared to the $\mathrm{FG}_{\mathrm{GLY} / \mathrm{GLA}}$ film, which was related to the impurities or residues from the raw material that remained in the film, such as proteins, lipids, and fiber. Although the concentrations of these components are low, they can interact with flaxseed gum and each other, which influences the final film structure. 
Table 2. Elemental analysis data of FG films.

\begin{tabular}{lccccc}
\hline Samples & $\mathbf{\% C}$ & $\mathbf{\% H}$ & $\mathbf{\% N}$ & $\mathbf{\% O}$ & \% Protein \\
\hline FG & 41.99 & 6.72 & 0.93 & 50.36 & 5.81 \\
FG $_{\text {GLY/GLA }}$ & 41.39 & 7.78 & 0.75 & 50.08 & 4.69 \\
FG $_{\text {GLY/GLA/HCl }}$ & 42.38 & 7.47 & 0.46 & 49.69 & 2.87 \\
\hline
\end{tabular}
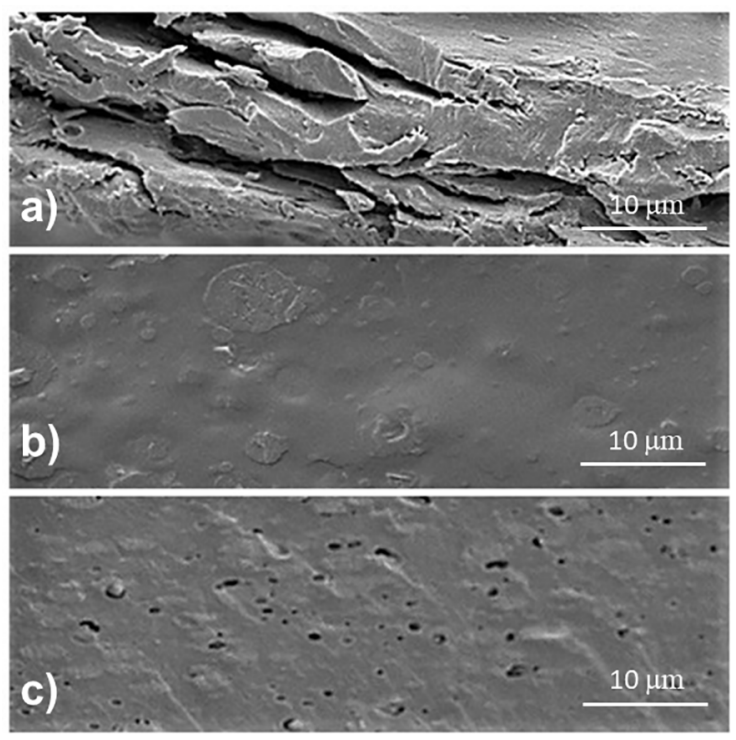

Figure 5. SEM micrographs of fractured region of films. a) FG, b) $\mathrm{FG}_{\mathrm{GLY} / \mathrm{GLA}}$ and c) $\mathrm{FG}_{\mathrm{GLY} / \mathrm{GLA} / \mathrm{HCl}}$ with a magnification of $3500 \mathrm{x}$.

The addition of glycerol and glutaraldehyde (Figure $5 b)$ allowed greater organization of the matrix, result in a more compact appearance. However, the presence of small domains is still observed which may be related to the small fraction of proteins that had a low dispersion at the $\mathrm{pH}$ studied. With the addition of $\mathrm{HCl}$ (Figure 5c) the sample had a more homogeneous appearance and a better distribution of these domains. However, the formation of pores was also observed. The addition of acid also resulted in a sticky appearance due to glycerol exudation on the surface. As mentioned above, the function of glycerol is as plasticizer, and with acts on the distance between the polymer chains. With the crosslinking process $(\mathrm{pH}=3.5)$ the glycerol loses space for crosslinks exceeding the surface of the film. Some authors have reported this behavior of plasticizer exudation on the film surface ${ }^{37}$.

For the nanocomposite originating from the addition of $\mathrm{CN}$, the presence of pores was not observed (Figure 6). Nevertheless, the rough appearance observed for the nanocomposites was due to the insertion of the filler, which created tortuous paths in the matrix, showed good aggregation and homogeneity with both components, which can contribute to better mechanical properties. With the increase of $\mathrm{CN}$, a decrease in the glycerol exudation effect was also evidenced.

\subsection{Solubility $(S)$}
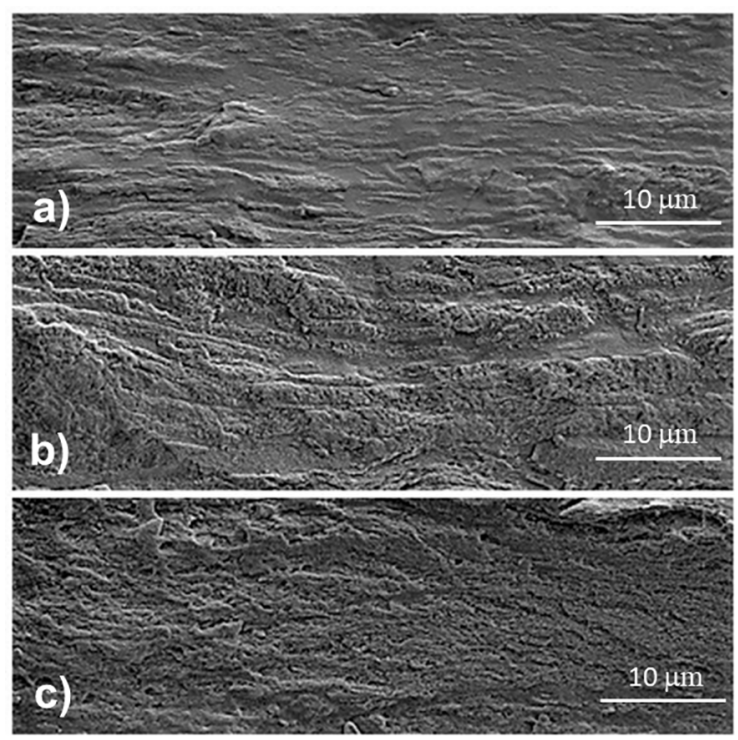

Figure 6. SEM micrographs obtained from fractured region of the FG nanocomposites. a) $\mathrm{FG}_{2 \% \mathrm{CN}}$, b) $\mathrm{FG}_{4 \% \mathrm{CN}}$ and c) $\mathrm{FG}_{8 \% \mathrm{CN}}$ with a magnification of $3500 \mathrm{x}$.

The water solubility data of the flaxseed gum films and nanocomposites are presented in Table 3. The neat FG and $\mathrm{FG}_{\mathrm{GLY} / \mathrm{GLA}}$ were completely soluble in water, suggesting in insufficient crosslinking of the polysaccharide chains, but in the presence of acid $\left(\mathrm{FG}_{\mathrm{GLY} / \mathrm{GLA} / \mathrm{HC}}\right)$, the sample showed a significant reduction, from $100 \%$ to $53 \%$. The decrease in the solubility in this case is compatible with the crosslinking process, which diminishes the solubility of the material in an aqueous medium.

The $\mathrm{CN}$ insertion contributed to the reduction of solubility for all nanocomposites in comparison with the $\mathrm{FG}_{\mathrm{GLY} / \mathrm{GLA} /}$ ${ }_{\mathrm{HCl}}$ film. According to Slavutsky and Bertuzzi, the reduction in solubility by the insertion of $\mathrm{CN}$ is indicative of strong interactions between $\mathrm{CN}$ with the matrix. These interactions confer stability and resistance to the composites obtained ${ }^{38}$. However, in the nanocomposite profiles, the higher amount of $\mathrm{CN}$ conferred higher solubility. There was a decrease in solubility with the addition of up to $4 \% \mathrm{w} / \mathrm{w}$ of $\mathrm{CN}$. Conversely, the solubility increased with the addition of $8 \%$ $\mathrm{w} / \mathrm{w}$, probably due to the increase in hydrophilic charge. This indicates that the $\mathrm{FG} / \mathrm{CN}$ nanocomposite reached its maximum water resistance when $4 \% \mathrm{w} / \mathrm{w}$ of $\mathrm{CN}$ was incorporated.

\subsection{Water absorption (Wa)}

The water absorption values from the films and nanocomposites are presented in Table 3. In general, the 
films and nanocomposites reached equilibrium after between two and three days. With the addition of glutaraldehyde and glycerol, there was a decrease in the water absorption value from $11.4 \%$ to $5.0 \%$. This may be associated with the more compact structure of the $\mathrm{FG}_{\mathrm{GLY} / \mathrm{GLA}}$ film compared to pure FG (Figure 5).

With $\mathrm{HCl}$ addition, the $\mathrm{FG}_{\mathrm{GLY} / \mathrm{GLA} / \mathrm{HCl}}$ film absorbed almost four times more water. This result was not expected as a decrease in solubility generally leads to a decrease in water absorption. Alternatively, water absorption can be influenced by porosity, which allows more water to be absorbed by the film, as suggested by the SEM image of the $\mathrm{FG}_{\mathrm{GLY} / \mathrm{GLA} / \mathrm{HCl}}$ film (Figure 5C).

With the addition of $\mathrm{CN}$ there was a considerable reduction in water absorption. Zhang and collaborators evaluated the incorporation of $\mathrm{CN}$ into soy protein and attributed low water absorption values to hydrogen bond interactions and physical crosslinking between $\mathrm{CN}$ and the matrix ${ }^{39}$.

\subsection{Contact angle}

The contact angle measurements are presented in Table 3 for all films and nanocomposites. The FG film showed an anomalous behavior, with a contact angle of $107^{\circ}$, exhibiting great hydrophobic character. This can be explained by the presence of soluble proteins and oil after the extraction of flaxseed gum in water, as reported by Kaushik and collaborators ${ }^{28}$. The contact angle of the $\mathrm{FG}_{\mathrm{GLY} / \mathrm{GLA} / \mathrm{HCl}}$ film was lower than the $\mathrm{FG}_{\mathrm{GLY} / \mathrm{GLA}}$ film, which was not expected due to increased crosslinking, which should result in a higher angle. Alternatively, the film's sticky appearance and the increase in the contact angle for the $\mathrm{FG}_{\mathrm{GLY} / \mathrm{GLA} / \mathrm{HCl}}$ sample justified, since wettability is a parameter directly related to surface interactions. Therefore a high concentration of glycerol favors wettability (lower contact angle) due to the hydrophilicity for both components (water and film surface).
The contact angle of the nanocomposites decreased with the addition of $\mathrm{CN}$ up to $8 \%$. This was attributed to the more hydrophilic character of $\mathrm{CN}$ compared to flaxseed gum. Reddy and collaborators also reported that the inclusion of CN promotes the contact angle decrease of agar films ${ }^{40}$. However, the $\mathrm{FG}_{8 \% \mathrm{CN}}$ nanocomposite showed an increase compared to nanocomposites, which may be justified by the decrease in glycerol exudation when a large amount of $\mathrm{CN}$ was added, promoting an increase in contact angle.

\subsection{Tensile tests}

The tensile results of the films and nanocomposites are displayed in Table 4. In the case of $\mathrm{FG}_{\mathrm{GLY} / \mathrm{GLA} / \mathrm{HCl}}$, this exhibited the lowest values of $\boldsymbol{\varepsilon}$ and $\sigma$ in comparison with the $\mathrm{FG}_{\mathrm{GLY} / \mathrm{GLA}}$ film. Glycerol exudation reduces its ability to act as a plasticizer. Furthermore, the increase in film water absorption generates structures with reduced tensile strength at the rupture. Alternatively, the addition of acid $(\mathrm{pH}=3.5)$ induced the formation of structures with higher resistance to water, corresponding to a greater degree of crosslinking. This is in contrast to the formulations in $\mathrm{FG}_{\mathrm{GLY} / \mathrm{GLA}}$ (no $\mathrm{pH}$ correction), which dissolved completely after 24 hours in water.

The linear behavior of $\sigma$ and $E$ values with the increase of $\mathrm{CN}$ was observed for the nanocomposites, showing a better mechanical performance and filler effect, to values greater than $2 \% \mathrm{w} / \mathrm{w}$ of $\mathrm{CN}$.

In fact, efficient reinforcement was only expected above the critical fraction of the filling phase volume, defined as the percolation threshold, which depends on the proportion of the nanoparticle. This suggests the formation of a rigid continuous network of nanocrystals bound through hydrogen bonds ${ }^{41}$. The filler percolation threshold was calculated from the aspect ratio found by microscopic observations and assuming a density of $1.045 \mathrm{~g} \mathrm{~cm}^{-3}$ (measured using a pycnometer) and $1.570 \mathrm{~g} \mathrm{~cm}^{-3} 42$ for $\mathrm{FG}$ and cellulose nanocrystals, respectively. The values calculated for $\mathrm{CN}$

Table 3. Interaction data of FG films and nanocomposites with water. Solubility, absorption and contact angle.

\begin{tabular}{lccc}
\hline Samples & $\mathbf{S}(\%)$ & $W a(\%)$ & Contact Angle $\left(^{\circ}\right)$ \\
\hline $\mathbf{F G}$ & 100 & $11.4 \pm 0.4$ & $107.0 \pm 0.8$ \\
$\mathbf{F G}_{\mathbf{G L Y} / \mathrm{GLA}}$ & 100 & $5.0 \pm 0.3$ & $80.0 \pm 0.6$ \\
$\mathbf{F G}_{\mathbf{G L Y} / \mathrm{GLA} / \mathbf{H C l}}$ & $53 \pm 1$ & $21.9 \pm 0.2$ & $70.0 \pm 0.6$ \\
$\mathbf{F G}_{\mathbf{2} \% \mathbf{C N}}$ & $27 \pm 1$ & $7.1 \pm 0.2$ & $50 \pm 1$ \\
$\mathbf{F G}_{\mathbf{4} \% \mathbf{C N}}$ & $20.8 \pm 0.4$ & $6.8 \pm 0.1$ & $53.0 \pm 0.7$ \\
$\mathbf{F G}_{\mathbf{8} \% \mathbf{C N}}$ & $42.82 \pm 0.04$ & $8.84 \pm 0.02$ & $65.0 \pm 0.3$ \\
\hline
\end{tabular}

Table 4. Tensile strength $(\sigma)$, elongation at break $(\boldsymbol{\varepsilon})$ and Young's modulus (E) of the FG films and FG/CN nanocomposite films.

\begin{tabular}{lcccc}
\hline Samples & Thickness $(\mathbf{m m})$ & $\boldsymbol{\sigma}(\mathbf{M P a})$ & $\boldsymbol{\varepsilon}(\boldsymbol{\%})$ & $\mathbf{E}(\mathbf{M P a})$ \\
\hline $\mathbf{F G}_{\mathbf{G L Y} / \mathbf{G L A}}$ & $0.044 \pm 0.004$ & $5.6 \pm 0.4$ & $58 \pm 1$ & $30 \pm 2$ \\
$\mathbf{F G}_{\mathbf{G L Y} / \mathrm{GLA} / \mathbf{H C l}}$ & $0.059 \pm 0.002$ & $2.1 \pm 0.4$ & $47 \pm 2$ & $6 \pm 1$ \\
$\mathbf{F G}_{\mathbf{2} \% \mathrm{CN}}$ & $0.067 \pm 0.002$ & $3.9 \pm 0.7$ & $57 \pm 2$ & $5.7 \pm 0.9$ \\
$\mathbf{F G}_{\mathbf{4} \% \mathbf{C N}}$ & $0.076 \pm 0.001$ & $5 \pm 2$ & $40.1 \pm 0.7$ & $45.1 \pm 0.2$ \\
$\mathbf{F G}_{\mathbf{8} \% \mathbf{C N}}$ & $0.099 \pm 0.005$ & $48 \pm 4$ & $79 \pm 14$ \\
\hline
\end{tabular}


were up to $2.8 \% \mathrm{w} / \mathrm{w}$. This is in agreement with tension values for $\mathrm{FG}_{4 \% \mathrm{CN}}$ and $\mathrm{FG}_{8 \% \mathrm{CN}}$.

As can be seen, the Young's modulus for $\mathrm{FG}_{8 \% \mathrm{CN}}$ was 13 times higher than for the reference sample $\mathrm{FG}_{\mathrm{GLY} / \mathrm{GLA} / \mathrm{HCl}}$ and $\mathrm{FG}_{2 \% \mathrm{CN}}$. The nanocrystal insertion enlarges the application and processing window of flaxseed gum, which presented low initial values of resistance that limit its use in any manufacture where greater stiffness is required.

\section{Conclusions}

The present work demonstrated that the crosslinking of FG with GLA at pH 3.5 resulted in different morphologies and properties, playing a fundamental role in the solubility of the films that proved to be more stable in water. However, an increase in water absorption and glycerol exudation effect was observed. Solubility, water absorption and the tensile strength and stiffness of the films were significantly improved with higher amounts of $\mathrm{CN}\left(\mathrm{FG}_{8 \% \mathrm{CN}}\right)$ addition. This was due to the enhancement generated by the strong interaction between $\mathrm{CN}$ dispersed into the polymer matrix. The materials described in this study are therefore able to improve the properties of flaxseed gum and may allow for application as bioplastics in food, agricultural and pharmaceutical industries.

\section{Acknowledgments}

The authors thank CAPES, CNPq, FAPEMIG and Federal University of Uberlândia for financial support.

\section{References}

1. Biscarat J, Charmette C, Sanchez J, Pochat-Bohatier C. Development of a new family of food packaging bioplastics from cross-linked gelatin based films. The Canadian Journal of Chemical Engineering. 2015;93(2):176-182.

2. Razzaq HAA, Pezzuto M, Santagata G, Silvestre C, Cimmino $\mathrm{S}$, Larsen N, et al. Barley B-glucan-protein based bioplastic film with enhanced physicochemical properties for packaging. Food Hydrocolloids. 2016;58:276-283.

3. Kowalczuk M, Adamus G. Mass spectrometry for the elucidation of the subtle molecular structure of biodegradable polymers and their degradation products. Mass Spectrometry Reviews. 2016;35(1):188-198.

4. Harmaen AS, Khalina A, Ali HM, Azowa IN. Thermal, Morphological, and Biodegradability Properties of Bioplastic Fertilizer Composites Made of Oil Palm Biomass, Fertilizer, and Poly(hydroxybutyrate-co-valerate). International Journal of Polymer Science. 2016;2016:3230109.

5. Accinelli C, Abbas HK, Little NS, Kotowicz JK, Mencarelli $\mathrm{M}$, Shier WT. A liquid bioplastic formulation for film coating of agronomic seeds. Crop Protection. 2016;89:123-128.
6. Chen C, Huang X, Wang L, Li D, Adhikari B. Effect of flaxseed gum on the rheological properties of peanut protein isolate dispersions and gels. LWT. 2016;74:528-533.

7. Fabre JF, Lacroux E, Valentin R, Mouloungui Z. Ultrasonication as a highly efficient method of flaxseed mucilage extraction. Industrial Crops and Products. 2015; 65: 354-360.

8. Warrand J, Michaud P, Picton L, Muller G, Courtois B, Ralainirina R, et al. Structural investigations of the neutral polysaccharide of Linum usitatissimum L. seeds mucilage. International Journal of Biological Macromolecules. 2005;35(34):121-125.

9. Muralikrishna G, Salimath PV, Tharanathan RN. Structural features of an arabinoxylan and a rhamno-galacturonan derived from linseed mucilage. Carbohydrate Research. 1987;161(2):265-271.

10. Li X, Wang Y, Li D. Effects of Flaxseed Gum Addition and Drying Conditions on Creep-Recovery Properties and Water Vapour Transmission Rate of Starch-Based Films. International Journal of Food Engineering. 2009;5(4):10.

11. Tee YB, Wong J, Tan MC, Talib RA. Development of Edible Film from Flaxseed Mucilage. BioResources. 2016;11(4):1028610295.

12. Wang Y, Li D, Wang L, Yang L, Özkan N. Dynamic mechanical properties of flaxseed gum based edible films. Carbohydrate Polymers. 2011;86(2):499-504.

13. Rana V, Rai P, Tiwary AK, Singh RS, Kennedy JF, Knill CJ. Modified gums: Approaches and applications in drug delivery. Carbohydrate Polymers. 2011;83(3):1031-1047.

14. Dutta PK, Tripathi S, Mehrotra GK, Dutta J. Perspectives for chitosan based antimicrobial films in food applications. Food Chemistry. 2009;114(4):1173-1182.

15. Janjarasskul T, Krochta JM. Edible Packaging Materials. Annual Review of Food Science and Technology. 2010;1:415-448.

16. Hager AS, Vallons KJR, Arendt EK. Influence of Gallic Acid and Tannic Acid on the Mechanical and Barrier Properties of Wheat Gluten Films. Journal of Agricultural and Food Chemistry. 2012;60(24):6157-6163.

17. Tropini V, Lens JP, Mulder WJ, Silvestre F. Wheat gluten films cross-linked with 1-ethyl-3-(3-dimethylaminopropyl) carbodiimide and N-hydroxysuccinimide. Industrial Crops and Products. 2004;20(3):281-289.

18. Khor E. Methods for the treatment of collagenous tissues for bioprostheses. Biomaterials. 1997;18(2):95-105.

19. Liu L, Liu CK, Fishman ML, Hicks KB. Composite films from pectin and fish skin gelatin or soybean flour protein. Journal of Agricultural and Food Chemistry. 2007;55(6):2349-2355.

20. Bao L, Yang W, Mao X, Mou S, Tang S. Agar/collagen membrane as skin dressing for wounds. Biomedical Materials. 2008;3(4):044108.

21. dos Reis EF, Campos FS, Lage AP, Leite RC, Heneine LG, Vasconcelos WL, et al. Synthesis and characterization of poly (vinyl alcohol) hydrogels and hybrids for rMPB70 protein adsorption. Materials Research. 2006;9(2):185-191. 
22. Döge N, Hönzke S, Schumacher F, Balzus B, Colombo M, Hadam S, et al. Ethyl cellulose nanocarriers and nanocrystals differentially deliver dexamethasone into intact, tape-stripped or sodium lauryl sulfate-exposed ex vivo human skin - assessment by intradermal microdialysis and extraction from the different skin layers. Journal of Controlled Release. 2016;242:25-34.

23. da Silva ISV, Flauzino Neto WP, Silvério HA, Pasquini D, Andrade MZ, Otaguro H. Mechanical, thermal and barrier properties of pectin/cellulose nanocrystal nanocomposite films and their effect on the storability of strawberries (Fragaria ananassa). Polymers for Advanced Technologies. 2017;28(8):1005-1012.

24. De France KJ, Chan KJW, Cranston ED, Hoare T. Enhanced Mechanical Properties in Cellulose Nanocrystal-Poly(oligoethylene glycol methacrylate) Injectable Nanocomposite Hydrogels through Control of Physical and Chemical Cross-Linking. Biomacromolecules. 2016;17(2):649-660.

25. Chattopadhyay DP, Patel BH. Synthesis, Characterization and Application of Nano Cellulose for Enhanced Performance of Textiles. Journal of Textile Science \& Engineering. 2016;6(2):248.

26. Kalia S, Sabaa MW, eds. Polysaccharide Based Graft Copolymers. Berlin, Heidelberg: Springer; 2013.

27. Babaee M, Jonoobi M, Hamzeh Y, Ashori A. Biodegradability and mechanical properties of reinforced starch nanocomposites using cellulose nanofibers. Carbohydrate Polymers. 2015;132:18.

28. Kaushik P, Dowling K, Adhikari R, Barrow CJ, Adhikari B. Effect of extraction temperature on composition, structure and functional properties of flaxseed gum. Food Chemistry. 2017;215:333-340.

29. Razmkhah S, Razavi SMA, Mohammadifar MA, Ale MT, Gavlighi HA. Protein-free cress seed (Lepidium sativum) gum: Physicochemical characterization and rheological properties. Carbohydrate Polymers. 2016;153:14-24.

30. Kumar P, Sandeep KP, Alavi S, Truong VD, Gorga RE. Preparation and characterization of bio-nanocomposite films based on soy protein isolate and montmorillonite using melt extrusion. Journal of Food Engineering. 2010;100(3):480-489.

31. Mazza G, Biliaderis CG. Functional Properties of Flax Seed Mucilage. Journal of Food Science. 1989;54(5):1302-1305.
32. Baltá-Calleja FJ, Vonk CG. X-ray Scattering of Synthetic Polymers. Amsterdam: Elsevier Science; 1989.

33. Henrique MA, Flauzino Neto WP, Silvério HA, Martins DF, Gurgel LVA, Barud HS, et al. Kinetic study of the thermal decomposition of cellulose nanocrystals with different polymorphs, cellulose I and II, extracted from different sources and using different types of acids. Industrial Crops and Products. 2015;76:128-140.

34. Burgos-Díaz C, Rubilar M, Morales E, Medina C, Acevedo F, Marqués AM, et al. Naturally occurring protein-polysaccharide complexes from linseed (Linum usitatissimum) as bioemulsifiers. European Journal of Lipid Science and Technology. 2016;118(2):165-174.

35. Liu J, Shen J, Shim YY, Reaney MJT. Carboxymethyl derivatives of flaxseed (Linum usitatissimum L.) gum: characterisation and solution rheology. International Journal of Food Science \& Technology. 2016;51(2):530-541.

36. Pawlak A, Mucha M. Thermogravimetric and FTIR studies of chitosan blends. Thermochimica Acta. 2003;396(1-2):153-166.

37. Gao C, Pollet E, Avérous L. Properties of glycerol-plasticized alginate films obtained by thermo-mechanical mixing. Food Hydrocolloids. 2017;63:414-420.

38. Slavutsky AM, Bertuzzi MA. Water barrier properties of starch films reinforced with cellulose nanocrystals obtained from sugarcane bagasse. Carbohydrate Polymers. 2014;110:53-61.

39. Zhang S, Xia C, Dong Y, Yan Y, Li J, Shi SQ, et al. Soy protein isolate-based films reinforced by surface modified cellulose nanocrystal. Industrial Crops and Products. 2016;80:207-213.

40. Reddy JP, Rhim JW. Characterization of bionanocomposite films prepared with agar and paper-mulberry pulp nanocellulose. Carbohydrate Polymers. 2014;110:480-488.

41. Flauzino Neto WP, Mariano M, da Silva ISV, Silvério HA, Putaux JL, Otaguro H, et al. Mechanical properties of natural rubber nanocomposites reinforced with high aspect ratio cellulose nanocrystals isolated from soy hulls. Carbohydrate Polymers. 2016;153:143-152.

42. Dufresne A. Interfacial phenomena in nanocomposites based on polysaccharide nanocrystals. Composite Interfaces. 2003;10(45):369-387. 